\title{
AS VIVÊNCIAS DO LAZER NA CULTURA GÓTICA ${ }^{1}$
}

Recebido em: 18/04/2009

Aceito em: 14/10/2009

Ana Paula Mukoyama Silva ${ }^{2}$

Escola de Artes, Ciências e Humanidades - EACH-USP

São Paulo - SP - Brasil

Edmur Antonio Stoppa ${ }^{3}$

Escola de Artes, Ciências e Humanidades - EACH-USP/GIEL/GPL São Paulo - SP - Brasil

RESUMO: O trabalho teve como objetivo analisar as vivências dos participantes da cultura gótica no seu tempo de lazer, na região central de São Paulo, a fím de compreender os sentidos e significados destas dentro da cultura gótica. Os principais resultados da pesquisa estão relacionados ao espaço enquanto ambiente propício à sociabilidade, ao encontro entre os participantes, além de outras questões relevantes e polêmicas como o consumo de diferentes drogas, conflitos verbais e/ou físicos entre diferentes culturas juvenis, o que aponta a precariedade das políticas públicas de lazer voltadas para a juventude, uma vez que tais problemas poderiam ser minimizados se a política de lazer da cidade, articulada com outras políticas sociais, tivesse um olhar mais sensível às características das diferentes culturas juvenis.

PALAVRAS-CHAVE: Atividades de Lazer. Adolescente. Cultura.

\section{THE EXPERIENCE OF LEISURE IN GOTHIC CULTURE}

ABSTRACT: The present study aimed to examine the experiences of participants from the gothic culture in their leisure time, in the central region of São Paulo, to understand the senses and the meanings within the gothic culture. The main search results are related to space, while the social environment conducive to the meeting between the

1 Artigo baseado no Trabalho de Conclusão de Curso apresentado no curso de Lazer e Turismo da Universidade de São Paulo.

2 Bacharel em Lazer e Turismo pela Escola de Artes, Ciências e Humanidades, da Universidade de São Paulo.

3 Docente do curso Lazer e Turismo, da Escola de Artes, Ciências e Humanidades, da Universidade de São Paulo. Membro do Grupo de Pesquisa em Lazer (GPL- FACIS/UNIMEP) e Grupo Interdisciplinar em Estudos do Lazer (GIEL-EACH/USP). 
participants and other relevant issues and controversies as the use of different drugs, verbal and/or physical conflicts between different youth cultures, which points to poor government policies aimed at youth recreation, since such problems could be minimized if the politics of leisure in the city, combined with other social policies, have a look at the most sensitive features of different youth cultures.

KEYWORDS: Leisure Activities. Adolescent. Culture.

\section{Introdução}

Esta pesquisa foi realizada com o intuito de analisar o desenvolvimento das vivências de lazer entre góticos em um espaço por eles freqüentado, situado próximo à Galeria do Rock, no Centro da cidade de São Paulo.

Para promover tal estudo objetivou-se compreender a identidade e as principais características do movimento gótico, estendendo-se aos sentidos e significados que ocasionaram a escolha de seus participantes por esta cultura juvenil.

O que tornou relevante a escolha dos góticos como objeto de pesquisa foi a participação destes em uma cultura juvenil pouco difundida e analisada. As informações relacionadas a esses jovens veiculados pela mídia, em geral, são de caráter chocante ou apresentam apenas informações relacionadas ao seu visual sombrio.

Tal situação pode ser encontrada no depoimento feito pelo missionário Romildo Ribeiro Soares (R. R. Soares), apresentador do Show da Fét, que, em um de seus programas, alegou que havia convertido uma gótica, pois ela "era um demônio e virou um anjinho" 5; ou em outra reportagem que descrevia os góticos como "jovens que

\footnotetext{
4 Programa religioso apresentado pelo Canal Bandeirantes, de terça a sábado às 20h30.

5 SÁ, Xico. Missionário Romildo Ribeiro tem estilo "bossa nova" de pregação. Folha Online, São Paulo, 17 janeiro 2003. Disponível em: http://www1.folha.uol.com.br/folha/ilustrada/ult90u30064.shtml. Acesso em: 14 jun. 2008.
} 
usam roupas escuras e ouvem música introspectiva”, e afirmava que ocorriam mais suicídios entre os góticos do que entre outros grupos juvenis ${ }^{6}$.

O mito do que é ser gótico também é discutido entre os jovens participantes ou não de outras culturas juvenis. Por exemplo, em um programa da Music Television (MTV), chamado Lavanderia ${ }^{7}$, houve um debate acerca desta temática, entre três góticas e três jovens sem preferências por quaisquer culturas juvenis, onde os participantes da cultura gótica foram questionados quanto ao porquê de sua escolha à inserção neste estilo e quais os aspectos positivos ou negativos decorrentes desta decisão.

Durante o programa diversos pré-conceitos foram expostos com relação ao movimento gótico, entre eles as afirmações que seus participantes são pessoas carentes, sem auto-estima e personalidade e que representam uma má influência para o resto da sociedade, devido à forma negativa como vivem e se vestem (como exemplos foram citados a cor preta das roupas, as músicas melancólicas e a ida a cemitérios).

Os góticos presentes no programa explicaram que eles têm uma vida normal, não são pessoas solitárias, carentes ou suicidas, e a escolha dessa cultura juvenil ocorreu devido ao gosto pela música, visual e ideais relacionados à mesma.

Eles ainda complementaram que não dormem em caixões, não fogem do sol e não cultuam as trevas ou o demônio, mas que se posicionam de forma contrária ao conformismo da sociedade e usam o excesso do preto para chocar e transpassar suas indignações.

Com a pesquisa aprofundada sobre a cultura gótica pôde-se verificar quais informações eram especulações que construíam um estereótipo da comunidade gótica e

6 FOLHA DE SÃO PAULO. Cientistas afirmam que góticos têm mais chance de se suicidar. Folha Online, São $\quad$ Paulo, 132006.2 Disponível em: http://www1.folha.uol.com.br/folha/mundo/ult94u94804.shtml. Acesso em: 14 jun. 2008.

7 Programa exibido no dia 27 de setembro à $0 \mathrm{~h}$. 
quais representavam a realidade vivida por este grupo. Em geral, o goticismo é visto como um espetáculo, algo que difere da realidade ou da vida cotidiana. Entretanto, a cena gótica possui normas, pressupõe estudos e conhecimentos, tem atividades e símbolos significativos e autonomia suficiente para ter sobrevivido por quase três décadas.

Esses indicativos exibem "um nível substancial de cultura, o que pode distinguir a cena gótica [...] que vai além de uma combinação de elementos passageiros entre os jovens, baseados em musica e estilo" (HODKINSON, 2002, p. 7).

Assim, os góticos possuem uma identidade, compartilham valores e um estilo irreverente e seus gostos que abrangem mais do que o vestuário e a maquiagem.

Contudo, muito de suas formas de reconhecimento ${ }^{8}$ usufruem de produtos de cultura de massa, bem como vestimentas, acessórios, estilos de cabelos, entre outros; e sua identidade se baseia em símbolos, vivências e atitudes delineadas por suas crenças e características específicas, as quais serão detalhadas no decorrer da pesquisa.

Quanto a optar pelo enfoque no tempo de lazer desta cultura juvenil, este foi justificado pelo desenvolvimento da mesma e a convivência dos participantes ocorrerem principalmente neste tempo, delineados por momentos de descontração, de sociabilidade, de descanso ou divertimento.

Segundo Magnani (2005, p. 176), essa ocorrência deve-se ao fato de que "as formas em que as experiências juvenis se expressam de maneira coletiva, mediante estilos de vida distintivos, têm como referência principalmente o tempo livre".

Além disso, a questão cultural entre os jovens não é freqüentemente trabalhada em pesquisas acadêmicas, ainda mais com enfoque no lazer. A mídia registra, 2005 . 
constantemente, o tema da juventude e suas coletividades, todavia as pesquisas e os estudos acadêmicos não apresentam tanto interesse nessa temática. Magnani (2000) ainda comenta que, quando o fazem, são estudos baseados no jovem relacionado a outro tema, como a política ou a educação, sem focar diretamente o tempo livre e as vivências que ocorrem durante o mesmo.

Considerando a gama de opções existentes, para os jovens a escolha do que seguir ou onde freqüentar não é tão simples. Porém, a partir de seus gostos, práticas e estilo, os mesmos têm a possibilidade de inserção em um grupo que compartilhe dos mesmos valores, ideais, desejos e afinidades. Desta forma, os jovens tendem a compartilhar locais e atividades que reflitam seus costumes e lhes propicie uma sensação intensa, um pertencimento.

A necessidade do pertencer, a escolha de um grupo para compartilhar suas afinidades, é um processo comum entre os jovens, como um rito de passagem. Porém, a cidade não apenas é parte ativa desse processo, mas pode, inclusive, influenciar o jovem, como ressalta Magnani (2002), afirmando que os moradores mantêm na cidade o seu estilo de vida, suas redes e formas de sociabilidade.

Assim, a cidade de São Paulo firmou-se como um pano de fundo atraente para a pesquisa, principalmente no caso do lazer e da cultura, por estes serem concretizados por meio de vivências e formas de apropriação dos espaços.

Entretanto, a concentração de espaços propensos ao lazer, no Centro da cidade e em outros locais, privilegia parte da população e minimiza o acesso de muitos, principalmente os indivíduos que residem nas regiões periféricas de São Paulo. Ao analisar a questão por este aspecto, tal concentração pode-se caracterizar como uma barreira de acesso ao lazer, pois os jovens de regiões mais afastadas têm poucas opções 
de lazer em suas proximidades e despendem de um tempo extenso/cansativo e de recursos financeiros para chegar ao Centro (MARCELLINO, 1996).

Enquanto metodologia, o estudo foi realizado mediante a combinação da pesquisa bibliográfica e empírica, o que levou à inserção da pesquisadora no espaço urbano utilizado pelos góticos para o desenvolvimento do seu tempo de lazer.

Quanto ao método, a etnografia, amplamente utilizada pela antropologia e em estudos relacionados à cultura, foi selecionada para o desenvolvimento da pesquisa a partir de três técnicas de coleta de dados para operacionalizar o estudo, sendo estas respectivamente: observação sistemática (MAGNANI, 2000), efetuada para reconhecer o espaço e absorver seus principais aspectos; seguida de observação participante (VEAL, 1997), que consistiu na convivência junto ao grupo estudado; e, finalmente, a aplicação de entrevistas semi-estruturadas (MARTINS, 2002), para aprofundar as questões observadas durante as técnicas anteriormente executadas.

A definição das amostras deu-se de forma não-probabilística, intencional, a partir dos critérios de acessibilidade e representatividade para o local e as pessoas relacionadas à cultura gótica (BRUYNE; HERMAN; SCHOUTHEETE, 1977), sendo que os nomes das pessoas entrevistadas na pesquisa foram omitidos nesse trabalho, a fim de preservar a identidade dos participantes.

\section{Entre a República e o Teatro Municipal: O Goticismo em Cena}

O tempo de lazer representa, nos dias atuais, boa parte do tempo em que a cultura gótica, bem como as demais culturas juvenis (BRENNER; DAYRELL; CARRANO, 2005), tem seu desenvolvimento. Nesse sentido, em relação ao entendimento do lazer em nossa sociedade por parte dos diferentes estudiosos da área, 
Marcellino (1987), elucida que dentre a maioria dos autores pode se perceber duas linhas de pensamento quanto ao lazer, sendo estas enfatizadas pelos aspectos atitude e tempo, prevalecendo atualmente a linha de pensamento que parte da combinação entre os dois aspectos, ou seja, o lazer é uma vivencia desenvolvida no tempo livre das obrigações e que pode trazer satisfação aos indivíduos.

Em relação aos locais onde essas vivências podem ser realizadas, estes podem ser denominados de equipamentos específicos e equipamentos não-específicos de lazer, dentre os quais se destacam a casa, o bar, a escola e a rua.

Quanto aos exemplos citados acima, alguns têm mais relevância para a cena gótica que outros. É o caso da rua, em especial as distribuídas pelo Centro da cidade, as quais inicialmente são consideradas áreas de locomoção e passagem, porém podem ser apropriadas por seus passantes, estendendo-as aos locais de convívio e troca de experiências.

Em relação aos locais urbanos onde há vivências de lazer, Magnani (2000), apresenta algumas categorias, tais como o 'pedaço', a 'mancha', o 'circuito'; definidas de acordo com as redes de relacionamentos estabelecidas entre os seus freqüentadores e os equipamentos, serviços ou espaços existentes.

Sobre o 'pedaço', o autor afirma que este é o:

[...] espaço intermediário entre o privado (a casa) e o público, onde se desenvolve uma sociabilidade básica, mais ampla que a fundada nos laços familiares, porém mais densa, significativa e estável que as relações formais e individualizadas impostas pela sociedade (p. 32).

A definição de Magnani (2000), sugere um espaço em que os freqüentadores se sentem familiarizados, se conhecem e onde as vivências de lazer são muito semelhantes. O pedaço tem como referência inicial os bairros, nos locais de lazer e sociabilidade, que 
estão próximos geograficamente.

Esse conceito foi estendido aos centros urbanos pela existência de pontos de encontro, apropriação de lugares para o lazer e todas as demais características semelhantes que esses espaços possuem com relação ao 'pedaço'. Todavia, há diferenças entre o 'pedaço' instituído no bairro e o instituído no centro urbano, pois neste, ao contrário do bairro, os freqüentadores não necessariamente se conhecem, mas sim se reconhecem, através de seus símbolos, gostos, e estilos de vida (MAGNANI, 2000).

Dentre os possíveis locais destinados ao lazer dos góticos, indagou-se a existência de 'pedaços' constituídos e como seriam as relações estabelecidas nos mesmos. Desta maneira, uma busca foi efetuada no centro de São Paulo entre os espaços freqüentados por estes, e um 'pedaço' foi definido, a Galeria do Rock e seu entorno, para a análise de seus integrantes e sua rede de relações, a partir da observação relacionada ao seu cenário, aos atores pelos quais ele é freqüentado e como são definidas as normas e símbolos que regulam esse ‘pedaço’ gótico.

Assim, a Galeria do Rock, em sua entrada pela Rua 24 de Maio, tem uma aparência decadente em relação ao espaço público, lojas e edifícios. A dinâmica da rua se apresenta silenciosa, apressada, marcada pelo movimento vasto de pessoas, com a quase ausência de carros, que traz a impressão de um calçadão.

Os pontos comerciais detêm toda a sua extensão e são pouquíssimos os lugares vazios, encontrados basicamente nos espaços em obras ou no início/final da Rua 24 de Maio. Quase todos os comércios da rua são voltados aos jovens e caracterizam-se por barracas de camelôs e lojas com produtos para o consumo, principalmente acessórios tais como brincos, cintos, correntes, colares, boinas, etc. 
A rua é "dominada" pelos jovens, em grupos, pares ou até mesmo sozinhos. Estes andam calmamente por sua extensão e a convivência entre os diferentes grupos que ali circulam é, em geral, pacífica, porém com pouca interação entres os mesmos.

Enquanto isso, no outro extremo da Galeria, na Avenida São João, tem-se a calmaria do Largo do Paissandu, espaço composto por um pequeno terminal de ônibus ao seu redor e uma igreja em seu interior e, além disso, encontram-se diversas barracas espalhadas que efetuam a venda de alimentos em geral.

Esta área do Paissandu poderia ser potencializada para o uso dos jovens, a fim de proporcionar-lhes uma extensão onde se desenvolva a sociabilidade e o lazer dos mesmos. Todavia, esta se encontra em ruínas por negligência da Prefeitura e de seus freqüentadores, apresentando uma quantidade significativa de moradores de rua e de prostitutas, com uma limpeza precária e a movimentação das pessoas, inclusive dos jovens, intensa e acelerada.

Ainda na Avenida São João, na calçada onde a Galeria está situada, há mais lojas, cinemas para o público adulto, com a exibição de filmes de sexo explícito, e uma banca de jornal. Ali a aglomeração juvenil acontece o dia todo, e o espaço se tornou ponto de encontro entre os participantes dos diferentes grupos que vêm passear na Galeria.

Avançando a observação para o interior da Galeria, aprofundou-se a análise do cenário e compreenderam-se algumas das razões pela escolha do 'pedaço' naquele ambiente. Este centro comercial é composto por quatro andares, mais um subsolo e um andar intermediário, entre o $1^{\circ}$ andar e o $2^{\circ}$ andar. Nos três primeiros pisos, as lojas e produtos são exclusivamente desenvolvidos para o público jovem, relacionados aos diferentes estilos que ali freqüentam, tais como punk, rock, gótico, heavy metal, 
hardcore, emocore etc. Entre os produtos e serviços ofertados estão roupas, acessórios, piercings e tatuagens, Compact Discs (CDs) e Long Plays (LPs), enfeites em geral e livros.

Já o quarto andar é dedicado às gráficas e alguns serviços de costura, os quais também se relacionam a temática da galeria. Um bom exemplo são os transfers em camisetas, que são vendidas nos andares abaixo e produzidas neste andar. A confecção de desenhos e logos para bandas menores também são feitos nesse espaço; e, por fim, as roupas mais exclusivas são solicitadas aos alfaiates presentes na galeria.

Em relação aos góticos, poucas lojas são voltadas aos seus interesses. Podem ser encontradas quatro apenas, sendo duas no $1^{\circ}$ andar, a Lady Snake e a Profecias (que possuem outras filais), e as outras duas no piso intermediário, a Black Rose e a Black Cat. Nestas lojas são vendidos todos os tipos de produtos relacionados ao estilo gótico, posteriormente detalhados na observação dos integrantes e seus acessórios.

A fim de compreender como são tecidas as relações dentro desse 'pedaço' gótico, atentou-se inicialmente para o ambiente onde este se estabelece e quais foram às razões para que este se desenvolvesse ali. Em seguida foi analisado o modo como os participantes da cena gótica se relacionam entre si e como se familiarizam com os demais grupos.

A mistura está presente entre os jovens de diferentes grupos que freqüentam a Galeria. Há uma série de estilos representados por uma imensa variedade de cores, sons e símbolos, onde cada indivíduo se esforça para expor sua originalidade por meio de aspectos propagados pelas suas roupas, seus cabelos e/ou seus adereços. Essa preocupação também foi observada por Abramo (1994), e apontada como uma característica importante da fase juvenil, pois ela pode auxiliar na construção identitária 
dos indivíduos.

Entretanto, simultaneamente, a maioria desses jovens expõe símbolos e características que representam a qual cultura juvenil eles pertencem ou simpatizam-se. Esta variedade de grupos se movimenta pelos andares da Galeria durante o dia, em busca de momentos de lazer e de consumo.

Ao anoitecer e com o fechamento dos estabelecimentos da Galeria, a sociabilização que ocorria em seu interior passa a ocorrer na calçada e no espaço à sua frente. Ali os jovens preenchem quase que completamente a rua e permanecem conversando, bebendo, namorando e escutando música.

Cada grupo permanece no seu espaço e possui características específicas, de modo que se pôde visualizar que os punks ficam mais à vontade sentados no chão, envolvidos em discussões coletivas e tomando bebidas de alto teor alcoólico como uísque e pinga. $\mathrm{O}$ grupo dos grunges também senta e até mesmo deita, mantendo-se em círculo, tocando violões e cantando os sucessos de suas bandas favoritas. O consumo de bebidas por parte deste grupo é marcado pela mistura de refrigerante, suco em pó e pinga ou vodka em uma garrafa pet de dois litros, que é dividida por todo o grupo. Já os metaleiros permanecem em pé, mas também se mantêm em uma roda. A conversa é constante e a bebida presente é a cerveja, principalmente as importadas.

Quanto aos góticos, estes ficam reunidos ao lado da banca de jornal, num círculo meio disforme e utilizam boa parte desse tempo para conversar, especialmente sobre músicas e eventos da cena.

As informações abordadas no quesito musical são: as canções preferidas, o que refletem suas letras e melodia e o quanto estas representam aos ouvintes. E a conversa se estende às bandas eminentes na cena, sua importância e relevância, questiona-se o 
surgimento de novas bandas e troca-se informações divulgando os shows.

Em relação aos eventos, discute-se sobre os próximos a serem realizados, mas principalmente, faz-se uma revisão dos que já ocorreram. Todos os detalhes do acontecimento parecem ser revividos, desde as bandas que se apresentaram e as músicas tocadas até a decoração do local e quem compareceu a essa balada.

Com base nestes elementos, pôde-se confirmar que os góticos são adeptos das conversas e do envolvimento com a música durante o período diurno como os jovens pesquisados em Brasília (CASTRO, 2002), caracterizando semelhanças entre o lazer dos góticos com os demais jovens.

Os góticos formam um dos menores grupos dentre os que se reúnem na Galeria, e a bebida fortemente consumida é o vinho tinto, que é adquirido em uma adega bem próxima à Galeria e é comercializado a preço de custo, o que aumenta o consumo da bebida entre os mesmos.

Há um respeito entre os grupos freqüentadores daquele ponto, entretanto suas diferenças afloram em alguns momentos e isso pode gerar conflitos entre eles. Os confrontos podem ser verbais ou físicos, e sua intensidade pode atingir inclusive outros grupos, que não estariam diretamente envolvidos nos mesmos.

A partir deste aspecto foram presenciados alguns momentos críticos na convivência entre os frequientadores da Galeria, desde pequenas discussões a grandes combates. O mais grave deles ocorreu no dia 04 de outubro, em um confronto de punks e skinheads que envolveu os demais grupos e, inclusive, pessoas que circulavam próximo àquela região no momento.

Já era final de tarde e a galeria acabara de fechar. Cerca de quinze minutos depois, um carro repleto de skinheads estacionou na saída da Av. São João e começou a 
agredir um grupo de punks que se reunia no local. Estes, que também costumam andar em gangues e manifestam-se como agressivos, continuaram com a briga, desferindo diversos socos e pontapés.

As circunstâncias tornaram-se mais críticas quando os punks decidiram atacar os "carecas" com três rojões, disparados sobre o grupo de skinheads, como se estes fogos de artifício fossem armas de fogo.

A partir deste momento, o caos se estabeleceu e as pessoas passaram a correr e se abaixar a fim de desviar dos disparos soltos a esmo no meio da rua. Rapidamente, todos se dispersaram, os feridos foram recolhidos por ambulâncias e, em seguida, a polícia foi chamada, mas ninguém foi detido.

Aparentemente, esse foi um caso isolado, marcado pela desavença entre os punks e os skinheads, porém as conseqüências envolveram e prejudicaram os demais grupos freqüentadores do espaço. No caso dos góticos, mesmo sem o envolvimento direto no confronto, muitos foram embora escondendo partes de suas roupas para evitar problemas com skinheads no caminho para casa, e os poucos que permaneceram se dirigiram a escadaria ao lado do Teatro Municipal para continuar conversando.

Na semana seguinte, na sexta feira, ao questionar o ocorrido com os góticos, eles disseram que há tempos os "carecas" não incomodavam, mas reconhecem a existência de conflitos entre os grupos, e afirmam que os skinheads também os confrontam. Segundo um gótico do local "[...] quando eles (os skinheads) vêm aqui, a "treta” rola com os punks, mas se eles (os punks) não estiverem aí, eles vêm causar para o nosso lado".

Nesta mesma data, os rumores sobre o confronto não haviam cessado e os "carecas" já alertavam que no sábado voltariam em maior número para revanche com os 
punks, devido os prejuízos sofridos por ocasião do conflito anterior ${ }^{9}$.

Para se proteger desse possível novo confronto, os góticos apareceram no pedaço "descaracterizados", para não serem nitidamente reconhecidos como participantes da cultura gótica. Sendo assim, por causa da confusão do dia 04 de outubro, no sábado seguinte, os góticos se apresentaram de forma neutra, com a presença da cor preta nas roupas, mas sem os símbolos e peças chaves de costume, evitando o sobretudo, o coturno, a maquiagem e os demais acessórios.

A atitude tomada pelos góticos, de evitar seu estilo por um dia para se resguardar, é explicada pelo fato de o grupo não ser violento e sempre procurar minimizar a participação em conflitos. Nesse sentido, Abramo (1994), citou algumas outras características que comprovam esta postura apaziguadora, como a formação dos góticos não ser configurada em gangues.

Logo, salvo nestes momentos problemáticos citados anteriormente, durante os finais de semana os góticos circulam em pequenos grupos, pela tarde no interior da galeria e apresentam-se, em geral, em pares ou trios formados por um único gênero, ou seja, meninas andam com meninas e garotos com garotos.

Nesse espaço, o principal ponto de encontro da cena é primeiro andar, entre as duas lojas que vendem produtos relacionados à cultura gótica. Ali os participantes permanecem por quase toda a extensão do dia ou enquanto os estabelecimentos encontram-se abertos.

Entre outros fatores, a concentração neste espaço é explicada pela facilidade de observar o que há de mais novo para se consumir, e também porque é nestas lojas que

9 Para mais informações sobre o confronto entre os skinheads e os punks, consultar BRAGA, T. Briga entre gangues deixa três pessoas feridas no centro de São Paulo. Folha Online, São Paulo, 05 de outubro 2008. Disponível em: http://www1.folha.uol.com.br/folha/cotidiano/ult95u452345.shtml. Acesso em: 14 out. de 2008. 
ocorre a divulgação dos eventos relacionados ao movimento. Ali se podem verificar os cartazes e os flyers com informações precisas de como, onde e o que vai acontecer no evento. Além disso, o espaço fica em um ponto estratégico da Galeria, de onde se pode observar quem chega e quem sai do local e quando é o momento se de confraternizar em um ponto mais espaçoso, fora da Galeria.

Enquanto o tempo passa, os participantes vasculham as lojas, depois se sentam no seu ponto de encontro e iniciam longas conversas, às vezes embaladas por alguma música. Durante o tempo que góticos caminham pela Galeria, ficou bem claro, a partir da observação do entorno, que este estilo é um dos que mais chama a atenção das pessoas que circulam pelo mesmo espaço.

A principal causa dessa curiosidade é a forma arrojada como o estilo e o visual gótico se compõe. Esse estilo baseia-se no espetáculo (ABRAMO, 1994), propositalmente para chocar e atrair os olhares dos demais às críticas implícitas em seu visual.

Inclusive, este se mostra como uma das principais inquietações do grupo; os retoques ao look, tanto nos cabelos, quanto na maquiagem e até mesmo nas roupas são comuns e ocorrem de forma natural enquanto estão conversando ou andando pelo local.

Tal situação alerta sobre o uso da imagem em si sem se preocupar com os ideais nela contido (ABRAMO, 1994), uma vez que a imagem que não expressa o conteúdo da cultura juvenil, deturpa o estilo e incentiva o modismo.

Sobre tal questão, $\operatorname{Souza}^{10}$ (1993, apud EMBACHER, p. 16, 1999), afirma que: “a moda é um dos instrumentos mais poderosos de integração e desempenha uma

${ }^{10}$ SOUZA, G. M. O espírito das roupas; A moda no século dezenove. São Paulo, Cia. das Letras, 1993. 
função niveladora importante, ao permitir que o indivíduo se confunda com o grupo e desapareça num todo maior”.

Para esta autora o modismo apresenta avesso ao estilo, por representar uma cópia de elementos numa organização aleatória sem nenhuma mensagem ou intenção prévia em sua utilização. Enquanto o estilo reflete uma identidade coletiva, aprimorada por elementos de gostos pessoais.

Somada a preocupação com a aparência, está a constante observação da figura do outro. Enquanto os góticos se deslocam, quase a desfilar, procuram nas pessoas ao redor mais de seus semelhantes para unir-se ao grupo. Esse gesto pode ser explicado pelos mesmos estabelecerem-se como um grupo reduzido, e que prontamente procura ser reconhecido e reconhecer outros possíveis adeptos ao movimento. Como observado por Magnani (2005), parte das formas de reconhecimento das culturas juvenis, incluindo a gótica, é efetuada por produtos de consumo, como roupas e acessórios, e Hodkinson (2002), complementa que as características estéticas são utilizadas como um mecanismo de reconhecimento entre os participantes.

Ao mesmo tempo em que parecem estrelar um espetáculo, os góticos mostramse pessoas tímidas, falam gesticulando, não conseguem permanecer parados - põe as mãos no bolso, tocam nos cabelos, nos acessórios, enfim, mostram ações consideradas trejeitos de timidez (WEIL; TOMPAKOW, 1986), como se os olhares dos outros os incomodassem, pela excessiva atenção que produzem.

Partindo para a observação de suas vestimentas, percebe-se a massiva presença da cor preta, que está presente também nos cabelos, nos calçados e na maquiagem. Dentre a escuridão encontrada nas roupas e acessórios, também são revelados alguns detalhes em outras cores relacionadas ao goticismo, como o roxo ou o vermelho. 
Entre as principais características encontradas nas vestimentas dos góticos destacam-se o sobretudo e o coturno, peças chaves de quase todos os visuais. Os cabelos são em geral curtos e ligeiramente raspados na nuca e, quando não, são extremamente longos e retilíneos. Dos outros acessórios presentes têm-se as meiasfinas, colares, brincos, coleiras, correntes, braceletes, cintos, corpetes, anéis, unhas pintadas ou postiças, coletes, piercings e tatuagens, ou até mesmo lentes de contato brancas ou vermelhas.

A face apresenta uma maquiagem carregada, delineada pelo preto consistente nos olhos e em alguns casos nos lábios. Para as moças, o vermelho carmim também é apreciado nos lábios, como citado por Hodkinson (2002), por influências diretas da cantora Siouxie Sioux, da banda gótica Siouxie and the Banshees.

Os detalhes distribuídos pelas roupas das góticas são variados e compõem grande parte da produção de seu visual, enquanto a maioria dos rapazes prefere a aparência mais “clean”, com peças lisas e com poucos adereços, mas existem exceções. Os participantes que aderem o estilo andrógeno, por exemplo, se utilizam de acessórios femininos para compor o visual, como blusas do tipo segunda pele, corpetes ou saias. Estes apresentam um visual tão carregado de elementos quanto às góticas.

Complementando as informações levantadas por meio da observação sistemática quanto ao cenário, atores e normas do local estudado, são apresentados na sequiência os dados coletados nas entrevistas semi-estruturadas e na observação participante relacionados ao envolvimento na cultura gótica, às principais vivências de lazer e às diferentes escolhas relacionadas ao espaço gótico.

Assim, com base nas informações descritas por Bourdoukan (2007), questionouse aos góticos quais eram seus símbolos e constatou-se que os mais utilizados são os 
religiosos: usados como brincos, pingentes colares e tatuagens. Cada gótico tem suas preferências, mas é necessário ter conhecimento sobre a sua escolha, verificando os significados pertinentes ao símbolo optado:

Logo, os góticos mantêm um código de ética com relação à escolha e utilização dos símbolos: caso estes sejam usados de forma inadequada, o grupo entende que o participante não está preparado para tê-lo e providenciam o resgate do mesmo.

Dentre os símbolos destacam-se o crucifixo, cruz de ansata ou $a n k h^{11}$, olho de hórus, a rosa cruz, o pentagrama e a cruz de São Cipriano (o feiticeiro). Bourdoukan (2007), também apontou que estes artigos religiosos representam a maioria dos símbolos, mas outros também são utilizados e remetem a aspectos da morte, como as caveiras e caixões. Ainda podem ser citadas imagens de vampiros e morcegos, refletidas em maquiagens, acessórios (como bolsas, lentes e dentes postiços) e tatuagens.

Ao anoitecer, o número de góticos aumenta e, enquanto a Galeria fecha lentamente, os mesmos se dirigem à sua saída, a da Avenida São João, em frente ao Largo do Paissandu, como os demais grupos, e formam uma concentração ao lado de uma banca de jornal.

Nesse ambiente, a descontração está mais clara: os góticos têm liberdade para beber, falar mais alto e parecem sentirem-se mais em casa. Os pares que antes circulavam pela Galeria de forma isolada agora se confraternizam e a interação entre estes é iniciada por um membro que conheça alguém já inserido no círculo, que se forma ao lado da entrada da Galeria, e este convida os demais a participarem do grupo. Todos os que participam da roda se cumprimentam, mesmo que não se conheçam.

Nota-se que há algumas diferenças no comportamento dos góticos em relação

11 Símbolo parecido com uma cruz, porém com a haste superior em formato oval, que na escrita egípcia referia-se ao símbolo da vida eterna. 
aos demais grupos, como, por exemplo, os punks ou os metaleiros. Os participantes do grupo estudado não se mantêm exatamente sob um círculo, havendo uma predisposição entre os pares a se aglutinarem, o que transforma o círculo em um disforme conjunto de duplas ou trios, que parecem traçar conversas próprias, entremeadas por conversas coletivas.

Uma posição similar ocorre com relação à música, pois os góticos não a compartilham de forma coletiva. Cada indivíduo ouve suas canções e bandas em seu próprio $m p 3$, e isso pode ocorrer, inclusive, enquanto conversam. Portanto, em ambos os casos os góticos se comportam diferentes dos demais grupos, que formam grandes rodas e mantêm as conversas e as músicas de forma coletivas, e todos os envolvidos parecem falar sobre o mesmo assunto ou produzirem/ouvirem o mesmo som.

Como comentado por Abramo (1994), há constante presença da música nos momentos de lazer e suas formas de consumo podem ser individuais ou coletivas, ocorrendo a primeira opção no caso dos góticos.

No decorrer das entrevistas, foi amplamente citada a importância da música, pois a partir dela os participantes iniciaram seu envolvimento com a cultura gótica. Os eventos produzidos são baseados nas bandas da cena e durante seus encontros no 'pedaço' ouve-se muita música.

Para um dos entrevistados, que é DJ, enquanto ocorre a discotecagem, as músicas apreciadas são um meio pelo qual ele expõe seus sentimentos e pode se expressar completamente, porque, segundo ele "[...] é onde eu demonstro, é um pouco do que estou ouvindo de música ultimamente e é uma forma de me expressar também, de jogar um pouco do que estou sentindo no momento [...]”.

Outra observação com relação à música diz respeito à sua temática. Esta foi 
citada por Bourdoukan (2007), como inspirada em imagens soturnas e entristecidas, contudo existem outros direcionamentos de temas e de melodias, como o Eletro Body Music (EBM) ou o Synth Pop, que são sons eletrônicos bem animados e dançantes.

Algo interessante notado também foi a freqüência com que estes jovens vêm à Galeria. Isso acontece pelo menos duas vezes por semana, principalmente na sexta e no sábado. Na sexta-feira os góticos se encontram no final tarde e início de noite, em torno das $17 \mathrm{hs}$, e permanecem juntos até o final da noite. No sábado o encontro ocorre mais cedo, por volta das $15 \mathrm{hs}$, e é a partir desse horário que os primeiros pares de góticos adentram a Galeria, com a convivência podendo se estender até o início da madrugada, se houver algum evento gótico na data.

Nos demais dias, a presença dos participantes é diferenciada, como aos domingos, quando a Galeria fica fechada. Como os eventos góticos ocorrem, geralmente, aos sábados, o domingo ainda é guardado por muitos para o descanso. E durante a semana, a maioria dos góticos que passam pela Galeria são os que trabalham dentro de suas lojas.

Foi possível perceber por meio da observação participante a assiduidade com que os participantes vão à Galeria. Durante o processo de pesquisa, verificou-se as mesmas pessoas se encontrando todos os fins de semana, e ao indagá-las sobre o porquê de vir aqui sempre, a resposta foi a possibilidade de encontrar os amigos, conhecer novas pessoas e sentir-se parte de um grupo, parte daquela cultura juvenil com a qual eles se identificam. Para um dos participantes "[...] é legal encontrar tanta gente no mesmo estilo que eu".

Estas pessoas ainda completam que vêm à procura de uma conversa, de um encontro, de um momento de convivência com seus semelhantes, pois "[...] aqui a gente 
curte mais com a galera que é difícil conseguir”.

Num determinado momento da observação, o número de integrantes do movimento gótico foi extremamente reduzido. Nessa ocasião os poucos que estavam na galeria permaneceram entre os seus pontos de encontro, impacientes e à espera de mais góticos para compartilhar aquele momento. Quando um deles adentrava a Galeria, o semblante do que o aguardava mudava e, rapidamente, ele se deslocava a fim de se encontrar e conversar.

Por estas questões pode-se perceber como os góticos formam um grupo reduzido, e desta forma mantêm uma forte união em sua convivência. Quando são poucos, os góticos se juntam aos punks, contudo a interação ocorre na "camaradagem", de forma mais superficial; eles poucos conversam, mas todos se cumprimentam e bebem juntos. Sobre esta questão, um entrevistado afirma que "a galera vem aqui para curtir a galera mesmo".

Devido ao movimento gótico não ser numeroso, a relação com outros grupos torna-se cotidiana e a predileção pela amizade com os participantes do movimento punk é explicada, primeiramente, porque o movimento gótico originou-se do punk, como uma alternativa menos agressiva de demonstrar seu descontentamento com os problemas existentes na sociedade.

Além disso, essa parceria traz a vantagem de se obter auxílio em um eventual conflito com participantes de outras culturas juvenis, como os skinheads. Visto que os góticos não são violentos, é evitado o envolvimento em confusões ao máximo, mas se estas ocorrerem, tiver os punks como aliados é um ponto positivo, pois estes são em maior número, seus participantes andam em gangues e são mais agressivos (ABRAMO, 1994). 
Ainda sobre as características dos góticos, entre os participantes observados nesse pedaço, a maioria procura um emprego ou trabalha com algo relacionado ao movimento, seja por meio de lojas, promoção de eventos, apresentações em casas de shows, vendas de produtos e acessórios de forma independente etc.

Outro dos entrevistados pode ser citado com um exemplo nessa questão. Ele afirma que: "[...] eu também faço parte dos eventos, pela Gothz Newz, que organiza eventos góticos e de rock em São Paulo, além de fazer parte da organização e ser DJ”.

Esse envolvimento com os locais e as instituições que compõem a cena gótica foi previamente explicado por Hodkinson (2002), como uma forma de os participantes se envolverem de forma integral com a cultura gótica, pois assim, inclusive nos momentos de trabalho, o participante mantém sua identidade. Um bom exemplo disto é a divulgação dos eventos na cena gótica, onde são os próprios participantes que distribuem os folders do evento, convidando a amigos, conhecidos ou pessoas que se mostrem interessadas pelo universo gótico.

Após o envolvimento com a divulgação, muitos deles se tornam promoters, remunerados ou não, dos eventos ligados à cena. E esse posto lhes traz algumas vantagens, como a entrada gratuita nos eventos promovidos e um maior conhecimento da cena gótica.

A propósito, esta cena encontra-se aglomerada, atualmente, no Centro de São Paulo, e a Galeria localiza-se geograficamente próxima às baladas freqüentadas pelos góticos. Nos seus arredores estão situadas casas noturnas que abrigam os eventos do movimento, e dentre as principais estão a Ocean Club, a Dr Phibes, Hotel Cambrigde e o Inferno. Essas casas não são voltadas ao público gótico de maneira exclusiva, mas reservam de um ou dois finais de semana para a realização de seus eventos. 
Anteriormente em São Paulo, os góticos tinham um local consagrado para as saídas noturnas, o extinto clube Madame Satã, que se situava à Rua Conselheiro Ramalho. Com a ausência de um local específico para o grupo, a alternativa encontrada pela cultura gótica foi a realização de diferentes eventos. Embora estes já ocorressem, a freqüência era quase trimestral, e atualmente cada evento ocorre a cada dois meses com temáticas variadas, e toda semana há pelo menos um pequeno evento programado.

Os eventos temáticos, mais concorridos, geralmente incluem de 9 a 10 bandas (entre covers e de som próprio) divididas em dois palcos, mais a discotecagem de 6 a 8 horas, contemplando diversos estilos musicais (EBM, Synth e Future Pop, 80's etc.). Além disso, ocorre sorteio de brindes (colares, corpetes, entre outros), performances artísticas, são servidas bebidas à vontade e o tempo de execução prolonga-se por toda a noite.

Já os eventos menores apresentam pouca infra-estrutura, geralmente uma pequena pista de dança e não tem uma extensa programação. Têm como atração principal apenas um DJ, que promove discotecagens especiais com as músicas de uma ou duas bandas por noite.

Além da Galeria do Rock, outro local próximo freqüentado pelos góticos é a escadaria lateral do Teatro Municipal. Geralmente, o local é utilizado como espaço de encontro pelos góticos quando a entrada da Galeria encontra-se lotada ou quando ocorre algum evento próximo ao Vale do Anhangabaú. Nesse espaço eles conversam, bebem e se preparam para o evento da noite, a ser vivenciado em uma das casas noturnas anteriormente citadas. Tal situação é apontada por um dos participantes que afirma:

[...] é como você está vendo agora: conversa, toma vinho e zoa, depois a gente ainda vai para o Bin Laden (bar próximo ao Anhangabaú), é 
um lazer total... Tanto que a gente se reúne aqui e vai pra balada, ou no Blackout ou na Ocean (ambas casas noturnas) [...].

A ida à escadaria também é uma forma de vivenciar o pertencimento ao movimento gótico, pois é neste espaço, bem como na Galeria, que o grupo se estabelece, se sente em um ambiente familiar e os participantes encontram pessoas que compartilham dos mesmos ideais e gostos que os seus, passando a conviver com outros semelhantes a eles.

Inclusive, esta também é utilizada como ponto de encontro para os góticos que não freqüentam a Galeria, por não desejarem confraternizar-se com demais grupos ou por não se identificarem com o local em questão, mas que procuram encontrar uma companhia para ir aos eventos da cena gótica.

Quanto às demais características expostas por Abramo (1994), em relação aos góticos, algumas delas foram confirmadas durante a observação participante. Isso pode ser visto na presença do estilo espetacular na cultura gótica, que aponta como os participantes usam do visual para revelar seus ideais e como o exagero nas mesmas é intencional como o objetivo de chocar e chamar a atenção dos demais às suas críticas.

Além disso, Abramo (1994), também cita como os góticos formam um grupo mais recluso e valorizam o individual acima do coletivo, pois durante a pesquisa pôdese verificar que as ações particulares são mais comuns e freqüentes que as coletivas, posição verificada com relação à construção do estilo, que é personalizado por cada participante, e pela forma de integração do indivíduo dentro do círculo disforme formado pelo grupo.

Os góticos mostram-se pessoas amigáveis e costumam aceitar pessoas de outros grupos no seu convívio, especialmente quando estas são amigas de participantes do 
‘pedaço' gótico. Todos os que chegam ao círculo são cumprimentados e participam da conversa sem distinções. A fala de um dos entrevistados aponta tal questão quando este afirma que "[...] a gente está aqui pra incluir cada vez mais pessoas, a gente não exclui ninguém $[\ldots] "$.

Um caso presenciado durante a pesquisa foi o de uma headbanger ${ }^{12}$ que convive com os góticos por apreciar a companhia deles e a estética do movimento.

Segundo ela,

[...] eu gosto dos góticos porque eles são mente aberta, conversam de boa e eles sabem que eu não sou gótica, eu gosto do visual e uso umas coisas, mas não sou gótica! E eles sabem disso. Meu coturno é militar, o dos góticos é diferente, com mais detalhes... São pequenos detalhes, mas faz diferença [...] (J.A. em conversa informal).

Inclusive, durante a observação, por diversas ocasiões foram ofertados convites para juntar-se ao grupo e participar de seu momento de lazer.

No decorrer da pesquisa de campo observaram-se as categorias de estilos analisadas na pesquisa bibliográfica e dois dos três principais estilos góticos elencados por Hodkinson (2002), foram presenciados no 'pedaço': o estilo sombrio e macabro, enfatizado pela adoração por vampiros, que tem um visual composto por camisa social e luvas pretas, capa preta por fora e vermelha por dentro e calça social sobreposta pelo coturno, ambos pretos.

Em tal estilo serão encontrados acessórios como colar preto com um pingente em formato de crucifixo na cor roxa, anéis em formato de caixão prateado, brinco na orelha esquerda e óculos com lentes azuis. Em ocasiões especiais são adicionados ao visual duas presas de vampiros falsas sobre os dentes caninos.

12 Indivíduo que aprecia o estilo musical conhecido como heavy metal e tem como característica principal a fidelidade às bandas de preferência, acompanhando e defendendo as mesmas em quaisquer circunstâncias. 
Referente ao segundo estilo citado por Hodkinson (2002), feminilidade $e$ ambigüidade, foi visto um participante adepto ao estilo andrógeno, marcado pela mistura de características femininas com as masculinas, que tinha em seu rosto uma maquiagem forte em vermelho e preto delineando os olhos e as sobrancelhas raspadas e lentes de contato brancas.

Quanto aos cabelos, estes eram longos, lisos e pretos, e a roupa era composta por uma camiseta branca, sobreposta por um corselete de vinil e uma jaqueta de couro, ambos pretos, finalizando com uma calça preta bem justa e coturnos até a altura do joelho. Por fim, os acessórios eram compostos por duas pulseiras, um cinto de rebites, dois brincos pequenos e óculos de sol sobre os cabelos. O terceiro estilo citado, fragmentado com outros estilos, não foi encontrado durante o tempo de observação.

Uma situação muito interessante encontrada durante a pesquisa é que, no interior do 'pedaço', o grupo dos góticos é formado por diferentes estilos, que se misturam e se integram e todos os participantes conseguem conviver de forma igual e compartilham da mesma identidade, não ocorrendo barreiras entre os góticos sombrios e macabros e os andrógenos, por exemplo.

Mesmo com esse ambiente favorável à interação, existem casos isolados de participantes da cena gótica que não se envolvem com esse grupo observado no 'pedaço'. Esses pares também caminham pelos mesmos espaços e lojas e revelam em seu estilo os símbolos do movimento, no entanto são imparciais aos outros participantes do movimento.

Quanto a esse aspecto, questionou-se ao grupo pesquisado o que poderia provocar tal afastamento e as razões citadas foram variadas, ocorrendo dentre elas: os participantes serem iniciantes no movimento, por isso tendem a se resguardarem e 
somente depois de adquirirem uma amizade "na galera" juntarem-se ao 'pedaço'. Outro caso mencionado foi o dos posers ${ }^{13}$, definidos como pessoas que não compreendem de forma clara o que significa e representa a cultura gótica, bem como quais as maneiras pelas quais esta se manifesta. Acredita-se que estes evitam o envolvimento com outros góticos por não apresentarem conhecimentos suficientes sobre o movimento.

Com o surgimento da questão dos posers indagou-se como era o "convívio" com as pessoas que procuram participar da cultura gótica de forma superficial e qual era a imagem que se formava sobre esses casos. A maioria do grupo concordou em dizer que é fácil reconhecer quem é "modinha" pelo visual e pelo "papo", pois não seguem os traços ou ideais da cultura gótica, embora tais pessoas não sejam desrespeitadas por isso no ambiente. Em uma conversa informal, um dos participantes do movimento diz que “[...] se um poser vem falar comigo, eu troco idéia de boa, mas é fácil sacar que ele não é do movimento".

Dentro do pedaço gótico também se pode observar que cada um de seus participantes recebe um apelido, pelo qual este passa a ser reconhecido no interior do grupo. A escolha é feita pela adição de uma palavra ao nome da pessoa e esta deve remeter a algo ou a um ícone que lhe seja representativo e/ou que reflita suas características, como por exemplo, Rafael Lacrimosa, onde a palavra escolhida representa sua banda favorita, na qual seu visual foi inspirado.

A convivência no 'pedaço' acrescenta ao participante informação com relação à cultura gótica, o prestígio em se desfrutar o tempo de lazer com seus similares, mas também possui aspectos preocupantes, verificados neste caso com o uso de drogas, que são utilizadas e oferecidas dentro do grupo, e cuja aquisição é feita por um ou dois

13 Pessoa que compreende superficialmente um determinado estilo e apresenta-se como um profundo conhecedor da cultura juvenil com a qual se identifica. 
membros do grupo que repassam as drogas aos demais. A compra dessa forma ocorre de maneira mais discreta e econômica. No caso das drogas mais caras, como a cocaína, os participantes a dividem e utilizam durante os encontros ou em baladas.

A observação do 'pedaço' gótico possibilita a realização de outras analogias com as informações previamente coletadas na pesquisa, como, por exemplo, o enquadramento da Galeria do Rock na categoria dos equipamentos não específicos de lazer (MARCELLINO, 1996). Este é um espaço voltado ao comércio de produtos relacionados ao rock e suas demais vertentes, planejado estritamente para essa função, e que atualmente representa mais do que um simples local para consumo.

Em seu ambiente conservam-se espaços onde grupos podem se encontrar e gozar de momentos de lazer e sociabilidade e, sendo assim, a Galeria pode ser compreendida como um caso similar ao bar e o barzinho, construído como um equipamento nãoespecífico de lazer que, com o tempo, passa a ser utilizado como um equipamento específico de lazer (CAMARGO, 1986), de forma que os seus visitantes a procuram mais como um local de entretenimento e desenvolvimento do que como um espaço de consumo, apesar de tal situação também acontecer entre os participantes da cultura gótica.

Outra questão a ser assinalada, refere-se aos equipamentos específicos de lazer situados no Centro da cidade de São Paulo. O estado em que estes se encontram é precário e, com isso, estes têm sido subutilizados ou, em alguns casos, abandonados, tanto pelos freqüentadores do Centro quanto pelo Governo. De acordo com Magnani (2002), a cidade em si já apresenta alguns aspectos que comprometem a qualidade dos locais de lazer, como a poluição, a violência, entre outros, e nestes casos observados, a situação é agravada pelo descaso do poder público, refletido na falta de investimentos 
na manutenção destas áreas e, conseqüentemente, a diminuição dos incentivos para que os jovens as utilizem.

A grande concentração de jovens em equipamentos não-específicos de lazer, como o local pesquisado, poderia ser mais bem distribuída com a revitalização dessas áreas, possibilitando opções de espaços para aproveitar o lazer. Além disso, espaços como a Galeria do Rock têm dificuldades para conter a aglomeração dentro de seus estabelecimentos. A administração da Galeria, por exemplo, visando o aumento do comércio em suas lojas, espalhou guardas e seguranças que controlam os grupos em frente às lojas ou as pessoas que ficam paradas nos corredores, além de pendurar placas que solicitam a circulação nos corredores.

Todas as informações coletadas compõem um retrato dos participantes da cultura gótica com relação ao seu estilo e aos aspectos que o compõem. Assim, são destacadas nas considerações finais as formas como os momentos de lazer são vivenciados e como essas características são relacionadas aos conceitos previamente estudados, relacionando-os aos dados coletados na pesquisa de campo.

\section{"Finalizando"}

Com relação aos objetivos traçados para a pesquisa, as vivências no tempo do lazer eram a principal questão, e sobre esta se verificou que os góticos mantêm no ‘pedaço’ um ambiente propício a conversas e integração. Para eles, o motivo da ida a esse espaço é poder estar entre os seus similares, adquirir mais informações sobre a cultura gótica e como esse movimento se desenvolve pela cidade de São Paulo, principalmente na região central, onde o 'pedaço' gótico esta situado.

A escolha da Galeria do Rock e de seu entorno como espaço referente à cultura 
gótica justifica-se, primeiramente, pelo fato de a Galeria ser um local propício ao surgimento de pontos de sociabilidade pela oferta de lojas e serviços relacionados aos jovens. Além disso, é no interior das lojas góticas que ocorre a divulgação dos eventos do movimento, e com isso os góticos passaram a se encontrar próximo às lojas, aproveitando para verificar os produtos disponíveis, os próximos eventos da cena e confraternizar com outros góticos.

A convivência com os góticos permitiu o entendimento de como são estabelecidas as normas no pedaço, uma vez que a iniciação no grupo só ocorre após a conquista da amizade de um dos atuais integrantes, ou seja, uma pessoa nova entra no grupo quando já conhece alguém ou é convidada por alguém.

Outra característica dos góticos que chegam ao espaço de convivência da galeria é que sempre cumprimentam a todos, mesmo que não os conheçam, e jovens participantes de outras culturas podem se envolver com o grupo sem distinções, situação verificada no caso da jovem headbanger e dos punks. Ainda nesse sentido têm-se o companheirismo dos góticos com os punks, situação explicada pela origem do movimento e pelo pequeno número de participantes que a cultura gótica apresenta na cidade de São Paulo.

Em relação à escolha desta cultura juvenil dentre as demais, as respostas foram variadas, contudo as mais freqüentes foram a liberdade de se expressar, o estilo de música, o visual utilizado pelos integrantes e a intenção de chocar, o que se relaciona com seus ideais.

Sobre seus principais símbolos e como estes eram utilizados, os participantes explicaram que a maioria dos símbolos relacionados à cultura é de caráter religioso, combinados a aspectos que lembrem a morte, como caveiras e caixões. Dentre os 
símbolos religiosos destacou-se o crucifixo, o ankh, o pentagrama, entre outros, e ainda explicaram que para se utilizar de um símbolo é necessário conhecer sua origem e seu significado, caso contrário o participante perde o direito de permanecer com o mesmo.

Além disso, outra posição confirmada na pesquisa de campo foi quanto ao pouco envolvimento dos góticos com a política, situação diferente dos punks, pois os góticos não têm um ideal relacionado a esta questão, uma vez que cada participante adere da maneira que preferir à sua escolha política.

Algumas comparações dos góticos no 'pedaço' com os demais grupos de jovens, como os punks ou os metaleiros, podem ser destacadas: no momento de lazer, por exemplo, as preferências de vivências são similares, tais como conversar, namorar e ouvir música. Porém, ao confrontar o comportamento em grupo, os góticos divergem dos demais, pois a individualidade se sobrepõe à coletividade e, esse fato ocorre tanto na disposição dos participantes (em um círculo disforme), quanto na forma de se integrar, seja por meio das conversas (em geral paralelas à conversa central do grupo) ou das músicas.

Um elemento crítico da participação no movimento gótico são os conflitos entre as culturas juvenis, que podem ser verbais ou físicos. Contudo, estes ocorrem com pouca freqüência e, declaradamente, apenas com o grupo dos skinheads que possuem divergências com os góticos.

Outros aspectos relatados durante a pesquisa bibliográfica, os quais foram citados como pré-conceitos em relação aos góticos, conforme as discussões realizadas na introdução deste texto, realmente não procederam na pesquisa de campo. Os participantes do 'pedaço’ gótico se mostraram pessoas alegres, amigáveis e “de mente aberta”, e em nenhum momento foram observadas situações relacionadas à destruição 
de patrimônio, invocações ao demônio e demais figuras ligadas às trevas, ou sequer citadas as questões do suicídio e da depressão.

Ao final do capítulo anterior foram expostas algumas analogias realizadas de acordo com os dados previamente pesquisados nas referências, e muitas das informações quanto à identidade, símbolos e características dos góticos foram confirmadas, bem como aspectos das culturas juvenis foram presenciados durante a pesquisa.

Verificou-se que a identidade gótica e suas principais críticas são transmitidas por meio de seus símbolos, utilizados em geral em acessórios como brincos e colares. As mensagens contidas nestes são explicadas por Bourdoukan (2007), em diferentes perspectivas, sendo a primeira referente ao reconhecimento, pois os símbolos são materializados para que os participantes góticos possam se identificar.

Em uma segunda justificativa, a autora exemplifica que a intenção do uso de artigos religiosos ou esotéricos reafirma o interesse em provocar o questionamento dos demais que os observam, naquilo que é chamado de "profanação do sagrado" (BOURDOUKAN, 2007, p. 72), que é a forma por eles encontrada para contestar o que discordam na sociedade. A mesma lógica pode ser remetida aos símbolos relacionados à morte, tais como as caveiras e o caixão.

Para ampliar a compreensão do cenário e as possíveis relações nele contidas, algumas sugestões foram feitas com relação ao aproveitamento dos equipamentos específicos de lazer que se encontram abandonados no Centro, visando uma melhor utilização dos mesmos em prol dos jovens.

Nesse sentido, as políticas públicas voltadas ao lazer são poucas até o momento, pois muitas áreas potenciais ao desenvolvimento do lazer não são bem aproveitadas, 
principalmente nas regiões periféricas na cidade de São Paulo.

Seria muito importante o poder público investir na ampliação do acesso ao lazer, em especial para a juventude, pois como citado anteriormente, os momentos de lazer são propícios ao desenvolvimento pessoal e social, nos quais ocorre a construção da personalidade e da identidade da juventude. Com isso, algumas das dificuldades envolvendo os jovens e seus locais de lazer poderiam ser minimizados com o aumento de opções de espaços e equipamentos para serem utilizados no cotidiano da cidade.

Conflitos como o verificado entre skinheads e punks na Galeria do Rock poderiam ser evitados caso a política de lazer de uma cidade como São Paulo tivesse um olhar mais sensível às necessidades e características das diferentes culturas juvenis, oportunizando mais e melhores espaços, além de programações específicas, sem a necessidade de esses grupos opostos terem que dividir o mesmo espaço, minimizando os possíveis confrontos pela cidade.

\section{REFERÊNCIAS}

ABRAMO, H. W. Cenas Juvenis: punks e darks no espetáculo urbano. São Paulo: Pagina Aberta, 1994.

BOURDOUKAN, A. Carpe Noctem - góticos na internet. In: MAGNANI, J. G. C.; SOUZA, B. M. (Org). Jovens na Metrópole: etnografia de circuitos de lazer, encontro e sociabilidade. São Paulo: Editora Terceiro Nome, 2007.

BRAGA, T. Briga entre gangues deixa três pessoas feridas no centro de São Paulo. Folha Online, São Paulo, 05 out. 2008. Disponível em: http://www1.folha.uol.com.br/folha/cotidiano/ult95u452345.shtml. Acesso em: 14 out. 2008.

BRENNER, A. K.; DAYRELL, J.; CARRANO, P. Cultura do lazer e do tempo livre dos jovens brasileiros. In: ABRAMO, H. W.; BRANCO, P. P. (Org.). Retrato da juventude brasileira: análise de uma pesquisa nacional. São Paulo: Instituto Cidadania/Editora Fundação Perseu Abramo, 2005. p. 175-214. 
BRUYNE, P.; HERMAN, J.; SCHOUTHEETE, M. de. Dinâmica da pesquisa em ciências sociais. Rio de Janeiro: Francisco Alves, 1977.

CAMARGO, L. O. L. O que é lazer. São Paulo: Brasiliense, 1986.

CASTRO, M. G.. O que dizem as pesquisas da UNESCO sobre juventudes no Brasil: leituras singulares. In: NOVAES, R. R.; PORTO, M.; HENRIQUES, R. (Org.) Juventude, Cultura e Cidadania. Comunicações do ISER, v. 21, 2002, p.63-90. Disponível em: http://www.naoviolencia.org.br/sobre/pdf/Unescoepesquisas MaryCastro.pdf. Acesso em: 27 jul. 2008.

EMBACHER, A. Moda e Identidade - A construção de um estilo próprio. São Paulo: Editora Anhembi Morumbi, 1999.

FOLHA DE SÃO PAULO. Cientistas afirmam que góticos têm mais chance de se suicidar. Folha Online, São Paulo, 13 abril 2006. Disponível em: http://www1.folha.uol.com.br/folha/mundo/ult94u94804.shtml. Acesso em: 14 jun. 2008.

HODKINSON, P. Goth: Identify, style, and subculture. Oxford: Berg, 2002.

MAGNANI, J. G. C. De Perto e de Dentro: notas para uma etnografia urbana. Revista Brasileira de Ciências Sociais, v. 17, n. 49, jun. 2002.

MAGNANI, J. G. C. Quando o campo é a cidade: fazendo antropologia na metrópole. In: . Na Metrópole. São Paulo: Edusp, 2000. p. 12-54.

. Os circuitos dos jovens urbanos. Tempo Social, Revista de Sociologia da USP, v.17, n. 2, nov. 2005.

MARCELlinO, N. C. Estudos do Lazer: uma introdução. Campinas: Autores Associados, 1996.

Lazer e Educação. São Paulo: Papirus, 1987. p.28-55.

MARTINS, Gilberto A. Manual para elaboração de Monografias e Dissertações. São Paulo: Atlas, 2002.

SÁ, X. Missionário Romildo Ribeiro tem estilo "bossa nova" de pregação. Folha online, São Paulo, 17 janeiro 2003. Disponível em: http://www1.folha.uol.com.br/folha/ilustrada/ult90u30064.shtml. Acesso em: 14 jun. 2008.

VEAL, A. Qualitive Methods. In: VEAL, A. Research Methods for Leisure e Tourism. London: Pearson Education: ILAM, 1997. p. 129-144.

WEIL, P.; TOMPAKOW, R. O corpo fala.- A Linguagem Silenciosa da Comunicação não-verbal. 57. Ed. Rio de Janeiro, Editora Vozes, 1986. 


\section{Endereço dos Autores:}

Edmur Antonio Stoppa

Ana Paula Mukoyama Silva

Avenida Brigadeiro Luís Antonio, 1041, apto 12,

Bela Vista - São Paulo - SP

CEP 01317-001 